\title{
Computational Diagnostics for Dielectric Barrier Discharge plasma
}

\author{
Thamir H. Khalaf and Zainab D. Abd Ali \\ Department of Physics, College of Science, University of Baghdad, Baghdad-Iraq. \\ E-mail: drthamirhameed@gmail.com, zainabdakheel4@gmail.com. \\ web site: http://www.scbaghdad.edu.iq/.
}

\begin{abstract}
The characteristics of electric discharge in a gap between two (parallel -plate) dielectric plates, which called dielectric barrier discharge (DBD), are studied for three dielectric materials Teflon, Glass and Silicon. The gap is filled with the argon gas in atmosphere pressure at ambient temperature. The separation of plates is $2 \mathrm{~mm}$ and each dielectric of $1 \mathrm{~mm}$ thickness and $10 \mathrm{~cm}$ in diameter. A sinusoidal voltage 750 with $50 \mathrm{kHz}$ frequency is applied to one of the dielectric plates, and the other plate is grounded. Fluid model (after solving Boltzmann equation) is used to simulate the discharge within the configuration.

The simulation results are showed a good diagnostics for the characteristics of the dielectric barrier discharge, through studying properties of breakdown of the gas, such as ,electric potential and field distributions, electron density, mean electrons energy, electrons and ions currents densities ,and the total plasma current density.
\end{abstract}

Keywords: Dielectric-barrier discharges; silent discharges; non-equilibrium plasmas.

\section{Introduction}

Dielectric barrier discharge (DBD) is a kind of gas discharges which was characterized by the presence of one or more insulating layers in the current path between metal electrodes [1]. Originally called silent discharge and also known as ozone production discharge [2], or partial discharge [3]. It was first reported by Ernst Werner Von Siemens in 1857 [4]. The presence of the dielectric precludes $\mathrm{dc}$ operation thus require alternating driving voltage with amplitude of typically $10 \mathrm{kV}$ with ranging from lower $\mathrm{RF}$ to microwave frequencies. Dielectric barrier discharges (DBDs) were attracted a lot of attention for past twenty years because it was considered as a source of non-thermal plasma and can achieved at atmospheric pressure with a wide variety of applications, [5]. Some of those applications are ozone generation, $\mathrm{CO} 2$ laser, lamp excimer, surface treatment, thin film deposition, pollution control, sterilization in biomedical and plasma screens etc. This largescale of industrial applications for DBDs because the absence of vacuum system, which made it more effective and lower cost than other gas discharges. In recent years many studies have been concerned with the effects of gas flow and electrode geometry on the discharge mode and characteristics. While several authors have published experimental and modeling studies of plane-parallel DBD at atmospheric pressure, under specific conditions, for instance, at least one of electrodes covered with a dielectric layer, an ac power with an appropriate frequency, etc. [6]

The present work is a numerical study for DBD in the Argon at atmospheric pressure. It consists of developing a one-dimensional numerical model with the aim to examine the properties of this discharge.

\section{The Electrodes configuration}

The configuration, which the study implemented within, consisted of two electrodes (as a pin) covered by a dielectric plates, Fig.(1). The thickness of each dielectric is $1 \mathrm{~mm}$ with diameter of $10 \mathrm{~cm}$ and the gap between dielectric plates is $2 \mathrm{~mm}$, the typical operating frequency is $50 \mathrm{kHz}$.

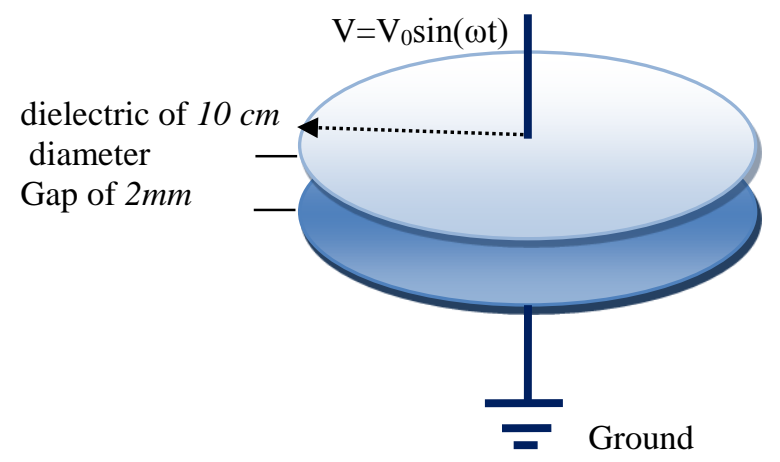

Fig.(1): The DBD configuration. 


\section{Modeling of the Problem}

The hybrid model which coupled between kinetic and fluid model is used, Numerical models of gas discharges must always be built upon a microscopic description of particles in the discharge. Most plasma models are built by solving the Boltzmann equation using the twoterm spherical harmonics expansion. In this model, the number density of the electrons are obtained by solving a continuity equation, whereas the electron transport coefficient (mobility and diffusion coefficient) and electron induced reaction rates are found from the solution of the Boltzmann equation [7]. Fluid models are used to describe the neutral and ionic species and the Poisson's equation is solved to obtain the electric field [8]. In this hybrid approach the fluid model provides the electron and ion densities, the electron mean energy and local electric field. These quantities are then used for the solution of the Boltzmann equation to obtain the EEDF. From the EEDF, electron induced reaction rates and electron transport coefficients are obtained. The transport coefficients and reactions rates are fed into the electron continuity equation to calculate the electron density. The reaction rates are also fed into the chemical kinetic model to determine the source and sink terms of different ionic and neutral species that are required for calculating the ionic and neutral species density. These species densities, in turn are utilized in solving the Boltzmann equation [9].

\section{Solving the Problem}

The solution of our problem for DBD is combination between solve BE (kinetic model) and solve continuity equation (fluid model) to calculate the required values for this work.

Calculations were begun with Used two term BE approximation Equation[7,10]:

$f(v, \cos \theta, z, t)=f_{0}(v, z, t)+f_{1}(v, z, t) \cos \theta$

From these two terms one can drive electron energy distribution function (EEDF)[7], Then used EEDF to get coefficients and rate coefficient for fluid equation and link these result with $\mathrm{BE}[7,10]$ :

$\frac{\partial f_{0}}{\partial t}+\frac{\gamma}{3} \varepsilon^{1 / 2} \frac{\partial f_{1}}{\partial z}-\frac{\gamma}{3} \varepsilon^{-1 l 2} \frac{\partial}{\partial \varepsilon}\left(\varepsilon E f_{1}\right)=C_{0} \ldots$ $\frac{\partial f_{1}}{\partial t}+\gamma \varepsilon^{1 / 2} \frac{\partial f_{0}}{\partial z}-E \gamma \varepsilon^{-1 l 2} \frac{\partial f_{0}}{\partial \varepsilon}\left(\varepsilon E f_{1}\right)=$

$-N \sigma_{m} \gamma \varepsilon^{1 l 2} f_{1}$

The right-hand side of equation (3) represents the change in $f_{0}$ due to collisions. The right-hand side of equation (3) contains the total momentum-transfer cross-section $\sigma_{m}$ consisting of contributions from all possible collision processes $\mathrm{k}$ with gas particles $[7,10]$ :

$\sigma_{m}=\sum_{k} x_{k} \sigma_{k}$

The electron and energy transport coefficient mobility $\mu_{e}, \mu_{\varepsilon}$ and diffusivity diffusivity $D_{e}, D \varepsilon$ are used as input in continuity equation for electron energy density by[7] :

$\Gamma=-\mu E_{n}-\frac{\partial(D n)}{\partial z}$

Also rate coefficient used as input reaction rate and is obtained from Equation [7]:

$k_{k}=\gamma \int_{0}^{\infty} \varepsilon \sigma_{k}(\varepsilon) f_{0}(\varepsilon) d \varepsilon$.

The reaction rate is obtain by [7]:

$R=\sum_{j=1}^{M} x_{j} k_{j} N_{n} n_{e}$

Where

$x_{j}$ is the mole fraction of the target species for reaction $j, k_{j}$ is the rate coefficient for reaction $j\left(\mathrm{~m}^{3} / \mathrm{s}\right), N_{n}$ is the total neutral number density $\left(1 / \mathrm{m}^{3}\right)$ reaction rate $\mathrm{R}$ is used as input in continuity equation for electron energy density which is[7,10]:

$\frac{\partial}{\partial t}(n)+\nabla \cdot \Gamma=R-(\mathbf{u} \cdot \nabla n)$

$n$ denotes the electron(energy) density $\left(1 / \mathrm{m}^{3}\right)$

$R$ is the electron (energy) rate expression $\left(1 / \mathrm{m}^{3} . \mathrm{s}\right), \mu$ is the electron(energy) mobility is $\left(\left(\mathrm{m}^{2} / \mathrm{V} . \mathrm{s}\right)\right), \mathbf{E}$ is the electric field $(\mathrm{V} / \mathrm{m}), D$ is the electron diffusivity $\left(\mathrm{m}^{2} / \mathrm{s}\right), \mathbf{u}$ is the neutral fluid velocity vector $(\mathrm{m} / \mathrm{s})$.

For calculate species density is used convection-diffusion- reaction equation [11]:

$\rho \frac{\partial}{\partial t}\left(w_{k}\right)+\rho(\mathbf{u} \cdot \nabla) w_{k}=\nabla \cdot j_{k}+R_{k}$

where 
$j_{k}$ is the diffusive flux vector, $R_{k}$ is the rate reaction for species $\mathrm{k}\left(\mathrm{kg} /\left(\mathrm{m}^{3} \cdot \mathrm{s}\right)\right)$, $\mathrm{u}$ is the mass averaged fluid velocity vector $(\mathrm{m} / \mathrm{s}), \rho$ denotes the density of the mixture $\left(\mathrm{kg} / \mathrm{m}^{3}\right), w_{k}$ is the mass fraction of the $k_{\text {th }}$ species

Finally, for calculated the electric field which depends on the space charge density according to Poisson's equation[8]:

$\nabla \cdot\left(\epsilon_{m} E\right)=-\nabla \cdot\left(\epsilon_{m} \nabla V\right)=\rho$ [8]:

The charge density is $\rho$ calculated by

$\rho=\sum_{i} q_{i} n_{i}$

With $n_{i}$ being a charged species density.

\section{The Results}

In this section, we will explore and discuss the output of the simulation of the dielectric barrier discharge (DBD) within the configuration that shown in Fig.(1). The results were got under a $(750 \mathrm{~V})$ sinusoidal voltage of $50 \mathrm{kHz}$ frequency, as shown in Fig.(2). It is applied on the upper electrode and the other electrode is grounded. The dielectric is different materials, (Glass, Silicon, and Teflon). The output from this studied are diagnostics to the characterization parameters of the DBD under the above conditions.

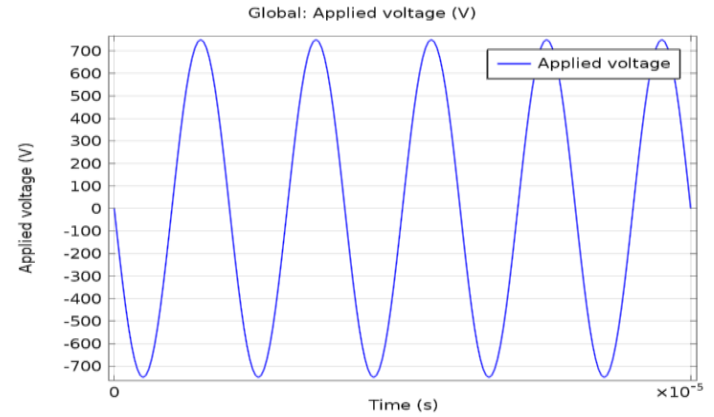

Fig.(2): The applied voltage as a function of time.

\subsection{Electric potential and field}

The electric field (depending on the potential) is the main parameter which affects the processes of DBD within the configuration. So that, the electric potential and field distribution, within the configuration, was shown below as surface plots. They are drawn in two dimensions (position and time). The variation of them are presented by color variations Fig.(3) shows surface plots for the potential distributions within the configuration for different three dielectrics are Teflon, glass, and silicon. The variation of the colors appeared the variation of the potential values in periodic form according to the frequency of the applied voltage and the distance from the electrodes. Also, the figure shows a same distributions for the three materials except the effect of the dielectric constant of each material. That effect is not clearly appeared in the figure.
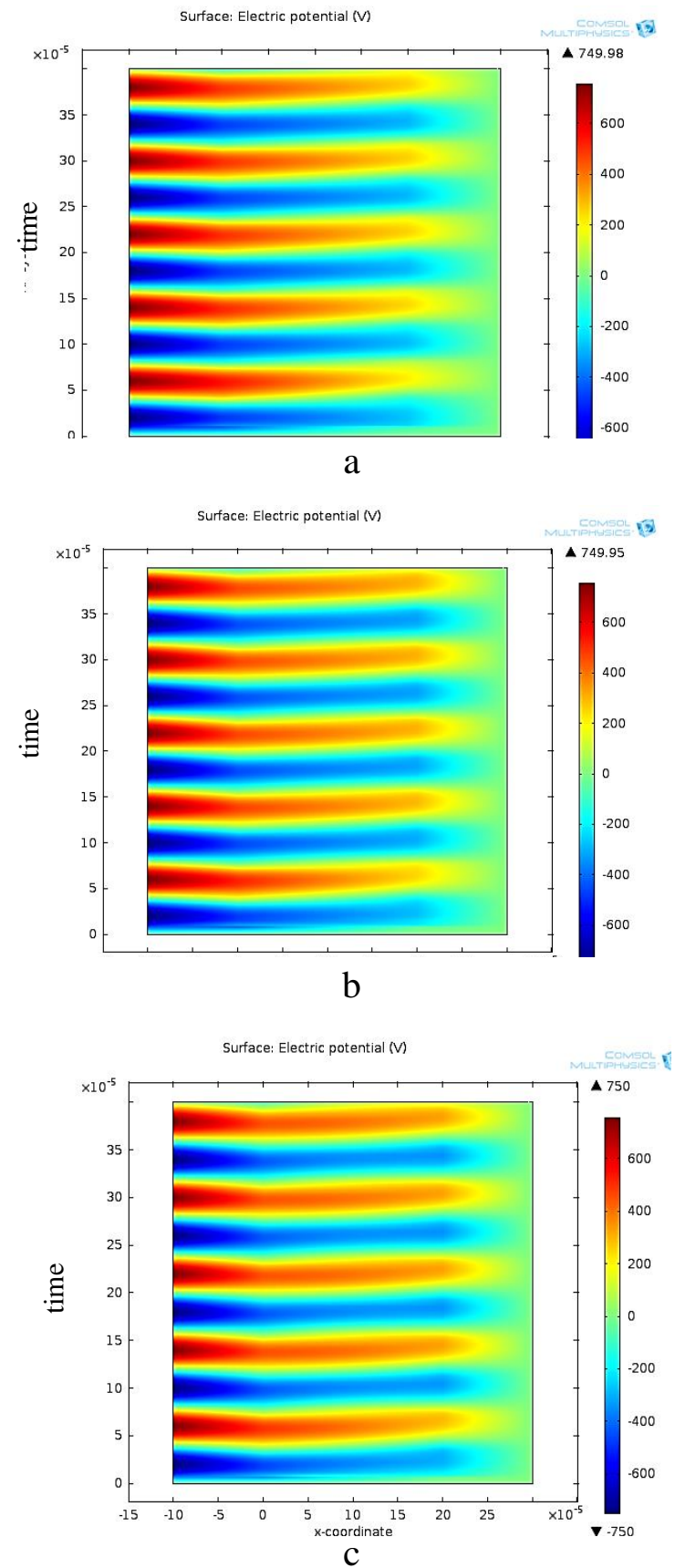

Fig.(3): Potential distribution within the configuration when the dielectrics are

a) Teflon, b) Glass, and c) Silicon. 


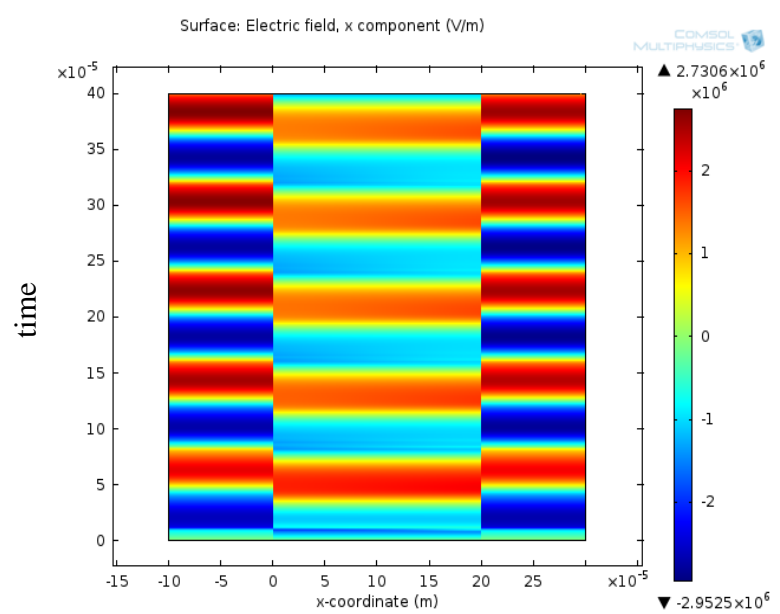

a

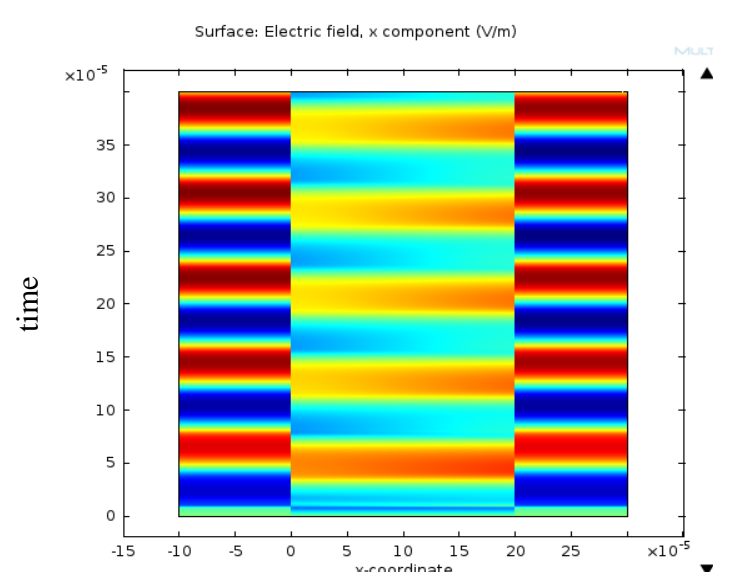

b

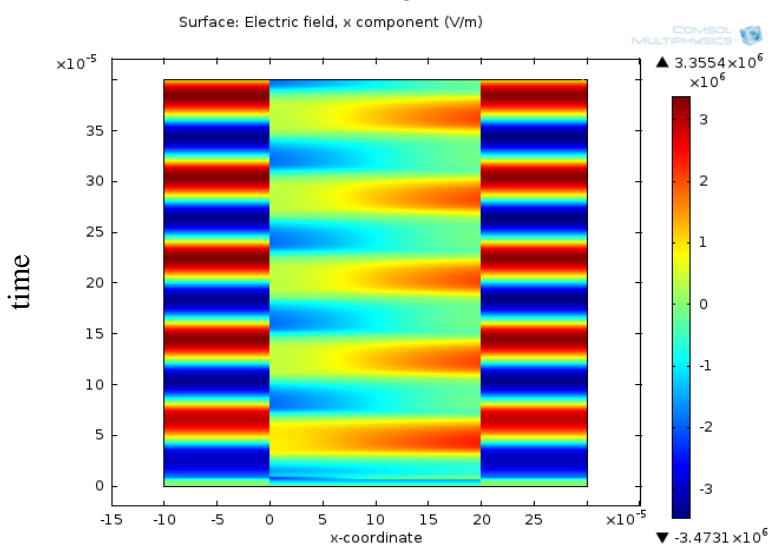

$\mathrm{C}$

Fig.(4): $x$ - component of the electric field distribution within the configuration when the dielectrics are a) Teflon, b) Glass, and c) Silicon.

Fig.(4) are shown the distribution for the xcomponent of the electric field within the configuration throw several waves periodic time according to the applied wave voltage. It shows clearly the effect of the dielectric materials. The electric field fluctuates uniformly within the dielectric materials while that less uniformly along the gas gap between the two dielectrics. That becomes clearer when the dielectric constant increases for glass and silicon.

\subsection{Electron Density}

The electrons, are playing the main role in different processes within plasmas, so that the variation of the electrons density produces different plasmas and then different applications.

Fig.(5) show diagnostics of the electron density along the argon gap between the dielectrics. That was done for different times (the experiment time) along the applied voltage wave and for different dielectrics, a) Teflon, b) Glass, and c) Silicon. All the curves in the figure appear high density of electrons near the two dielectrics which cover the electrodes, and the density decreases toward the mid of the gas gap. Also, one can observe decreasing of the density from the peak of it toward the dielectrics, that was well known as plasma sheath, and it is because the escape of electrons to the dielectrics.

It can be observed, also, from Fig.(5) that, the electron densities with the increasing of the experiment time which explain the development of the ionization process throw the time leading to the discharge. And the density increases with the increasing of the dielectric constants for the dielectric materials.

Finally, one can observe that, the plasma sheath region increases with the increasing of time and with the increasing of the dielectric constants. That is because the effect of the dielectric constant on the electric field in the region.

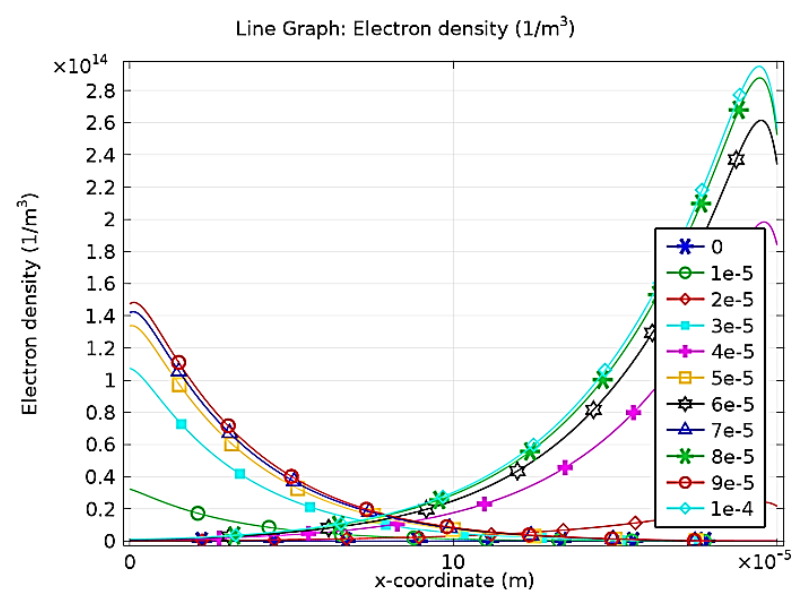

a 


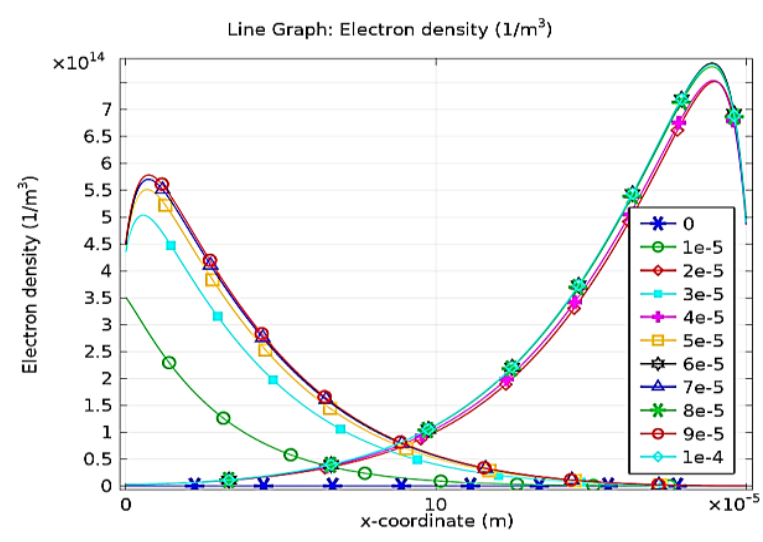

b

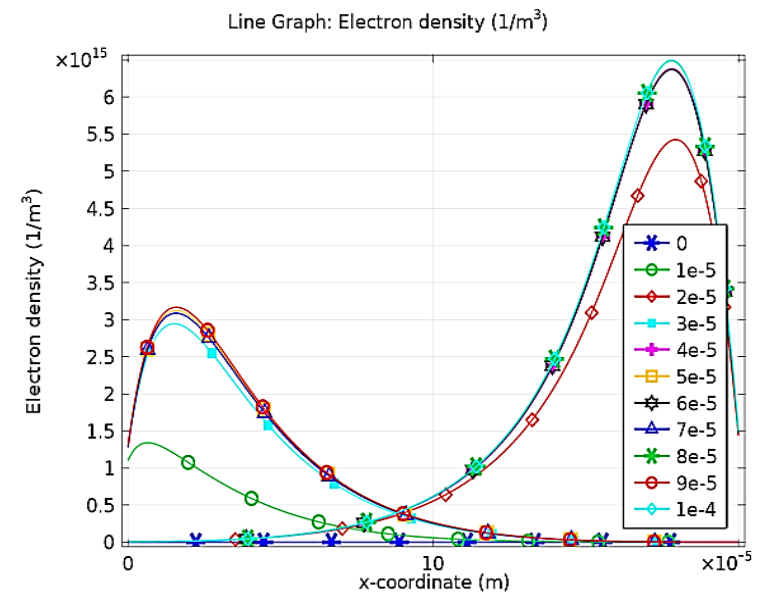

$\mathrm{c}$

Fig.(5): Electrons density along the argon gap as a function of $x$-coordinate for different times for a) Teflon, b) Glass, and c) Silicon.

\subsection{Mean Electron Energy}

The electron energy (equivalent to electron temperature) is one of the most important parameters which characterizing the plasmas. One of the diagnostics of is the mean electron energy along the gas gap throw the experiment time and for different dielectrics materials, a) Teflon, b) Glass, and c) Silicon. That was shown in Fig.(6). The (SI) unit for the energy is the volt, $\mathrm{V}$.

The Fig.(6), especially in the Teflon case, a, shows different behaviors in increasing and decreasing of the electron energy with the increasing of the experiment time. Otherwise, all curves show, approximately, the energy not varied along the gap except in plasma sheath regions near the dielectrics where the electron density decreases. While in the cases of glass, $\mathrm{b}$, and silicon, c, a different behavior becomes clearly that the electron energy is higher where the electron density is high and decreases toward the mid of the gap. Also the energy decreases at the plasma sheath regions.

Also, one can observe in all cases that the electron energy increases with the increasing of the dielectric constant of the materials. And silicon case, in some times, the energy becomes less than the energy of the initial electrons near the dielectrics. The variation of the energy was controlled by collisions within the gap which depend on the density.

\section{4. Electron Current Density}

Another important characterization parameter for plasmas is the electron current density. It was found and presented, in Fig.(7), as a function to the position along the gap length for different times and different dielectric materials, a) Teflon, b) Glass, and c) Silicon.

Fig.(7) shows that, the $\mathrm{x}$ - component of electron current density has the high values near the dielectric of the anode after each negative half of the applied voltage. While after each positive half, it has its high valued near the dielectric of the dielectric of the cathode. That was accepted because of the polarity of the electrode according to the applied voltage. Also, one can observe the decreasing of its values towards the other electrode.

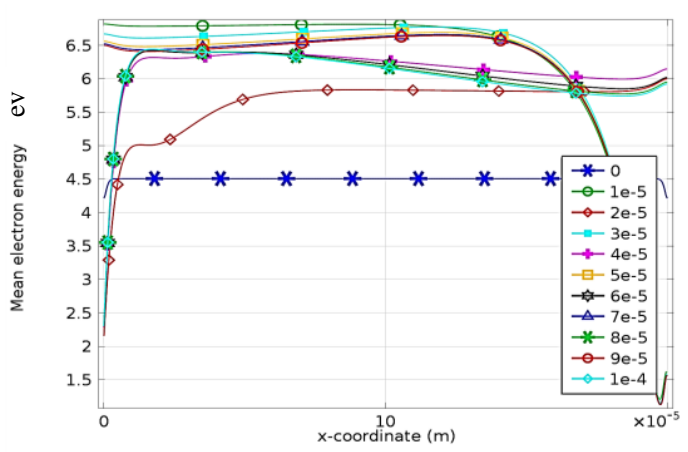

a

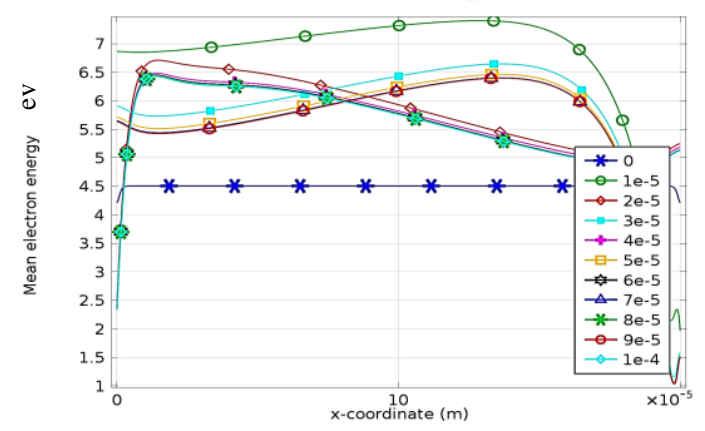




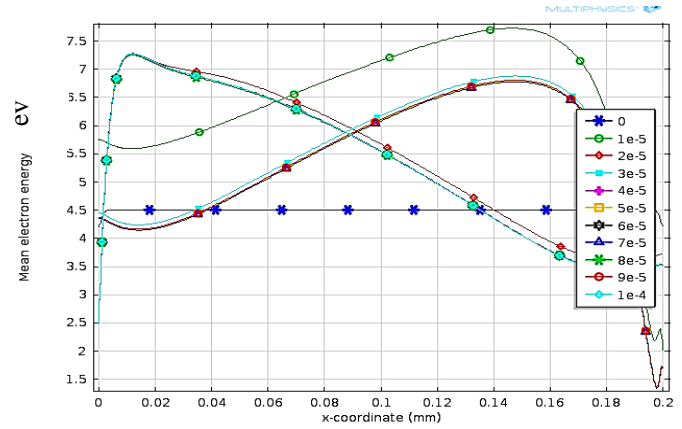

$\mathrm{c}$

Fig.(6) : Mean electrons energy as a function of a gap distance different discharge time for: a) Teflon, b) Glass, and c) Silicon.

Another observation can be noted from Fig.(7) that, the current increases with time and this increasing disappear with the increasing of dielectric constant. While it increases clearly, for all times with the increasing of the dielectric constants.

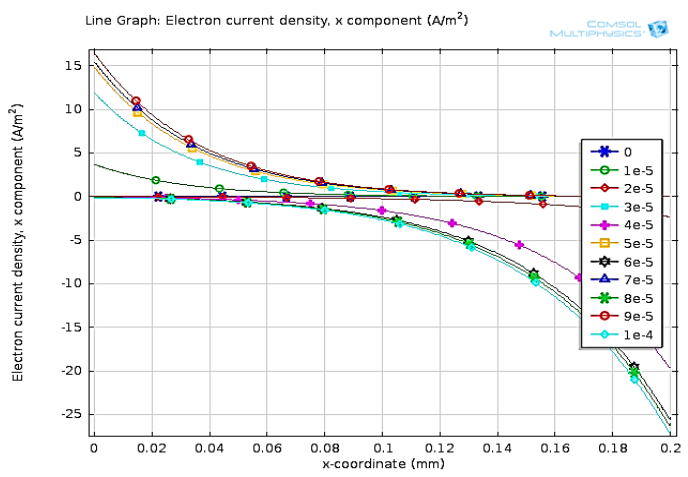

a

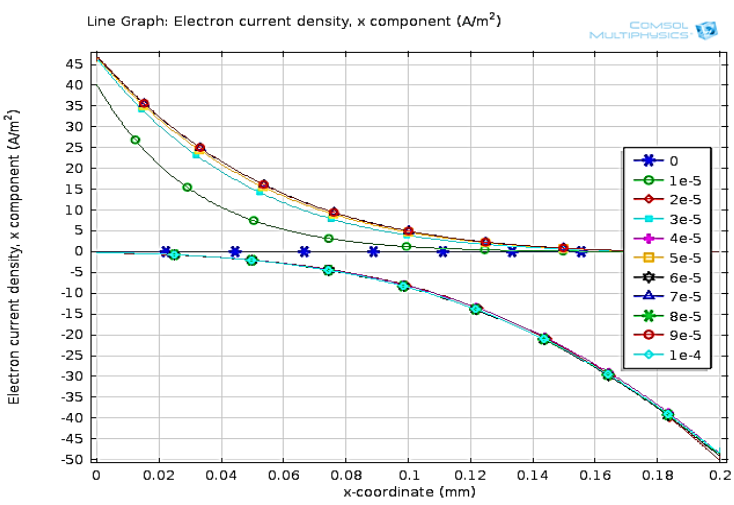

b

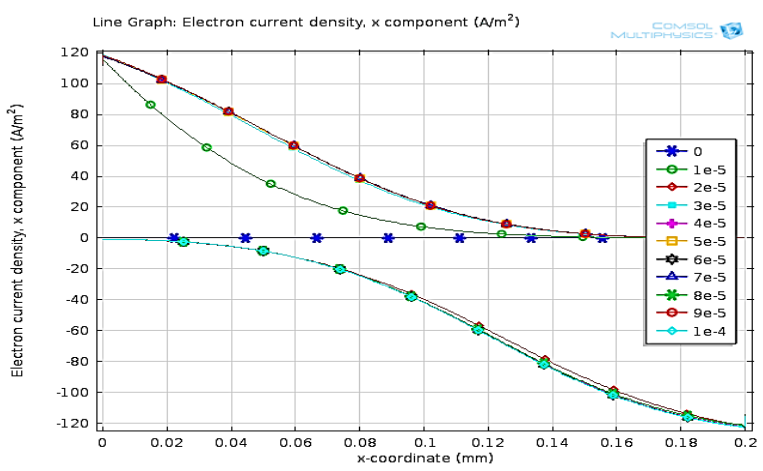

c

Fig.(7): Electrons current density as a function of a gap distance different discharge time for: a) Teflon, b) Glass, and c) Silicon.

\subsection{The Ion Current Density}

In the opposite direction of the electron current, the ion current follows in this DBD in the configuration. Fig.(8) shows this current density which calculated in this simulation. It shows the same behavior for the electrons current, Fig.(7), but in the opposite direction. In other words, the ion current density has the high values near the dielectric of the cathode after each negative half of the applied voltage. While after each positive half, it has its high value near the dielectric of the anode. And that was accepted because of the polarity of the electrode according to the applied voltage. Also, one can observe the decreasing of its values towards the other electrode.

In addition, one can note from Fig.(8) that, the ion current density increases with time and this increasing disappear with the increasing of dielectric constant. While it increases clearly, for all times with the increasing of the dielectric constants. And there is a fluctuation in the values in the shath region because the interactions with the dielectric surface.

\subsection{The Total Plasma Current Density}

The total plasma current is a sum of the electrons and ions currents, so that it has, approximately, the same value along the argon gas gap for each time as shown in Fig.(9). Also the total current density increases with time and becomes fixed when the dielectric constant increases which clearly appeared in the case of the silicon dielectric material.

Also, and as in the cases of the electrons and ions currents densities, the total plasma current density increases with the increasing of 
the dielectric constants, a) Teflon, b) Glass, and c) Silicone in Fig.(9).

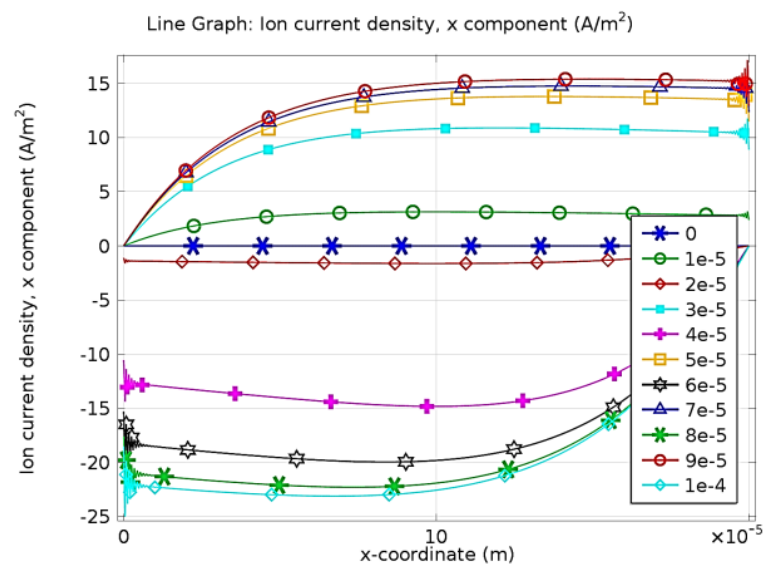

a

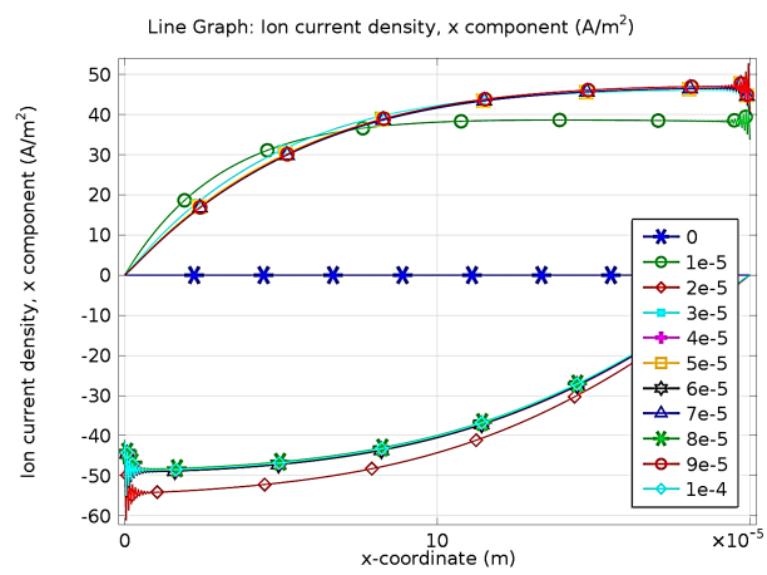

b

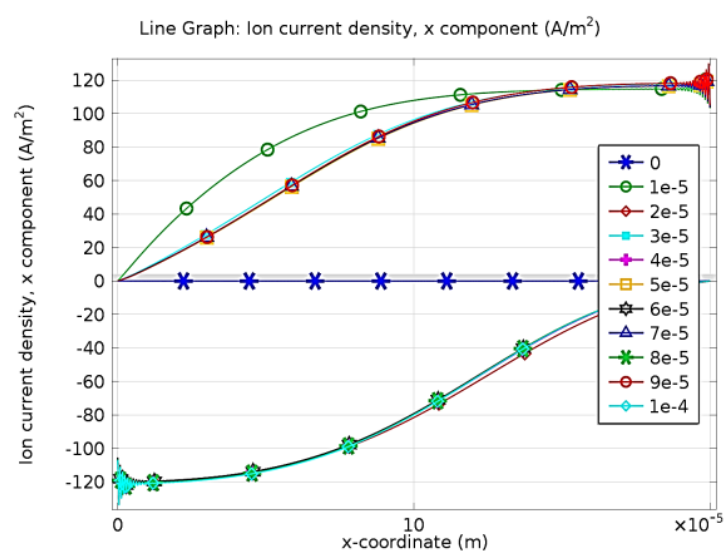

$\mathrm{c}$

Fig.(8): Ions current density as a function of a gap distance different discharge time for:

a) Teflon, b) Glass, and c) Silicon.

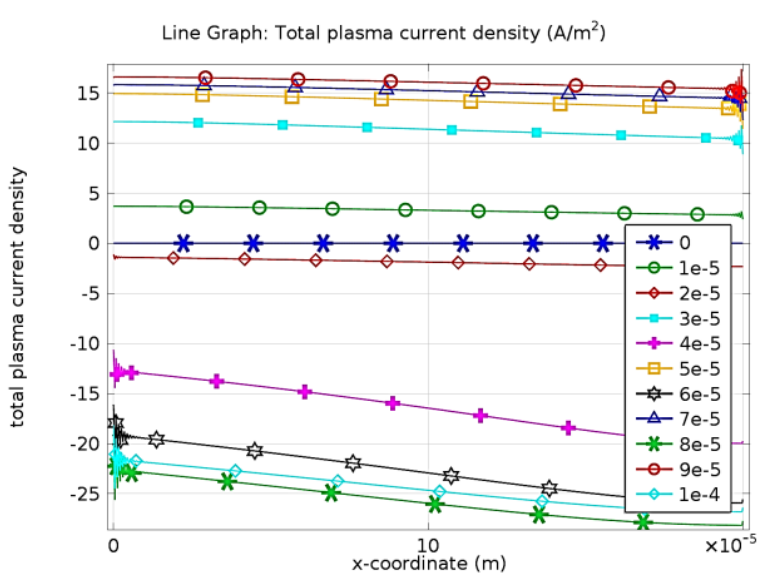

a

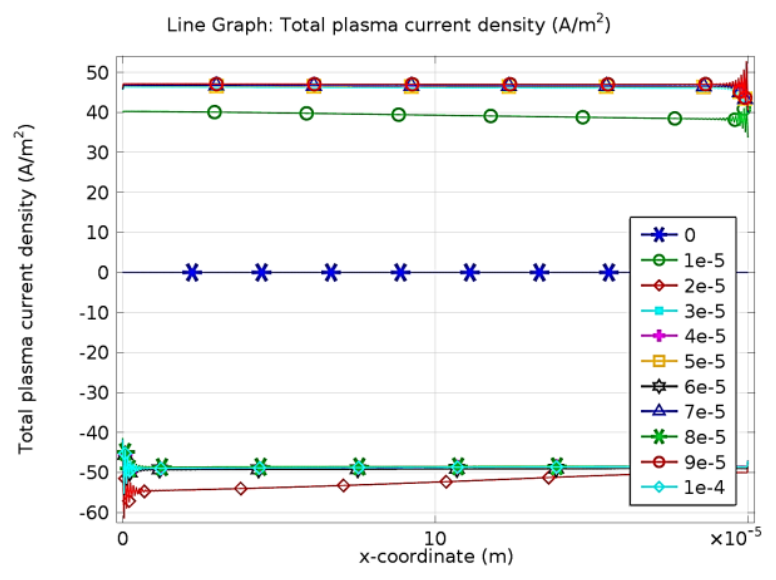

b

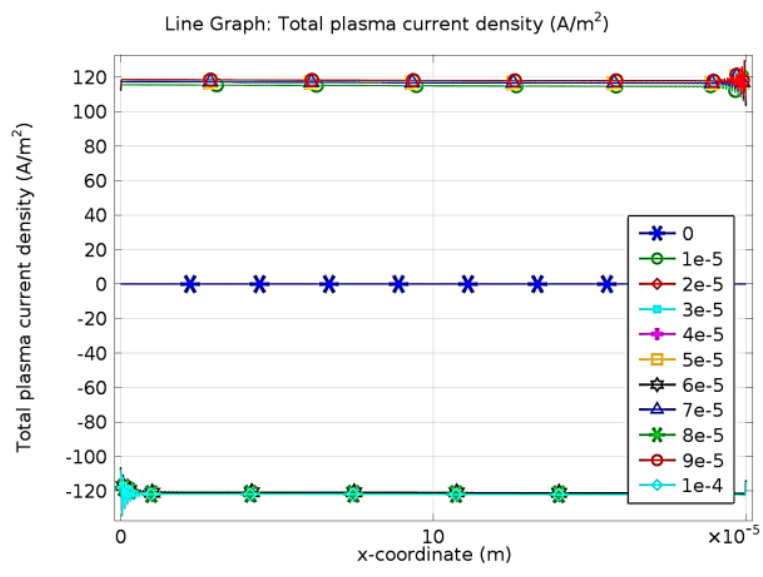

$\mathrm{c}$

Fig.(9): Total plasma current density as a function of a gap distance different discharge time for: a) Teflon, b) Glass, and c) Silicon.

\section{Conclusions}

In this work, a numerical diagnostics were obtained for the plasmas which produced by the DBD. From the results, one can conclude the following:

The computational procedure can give good diagnostics for plasma properties without cost device as in the experimental procedures 
which it was difficult because the small volume of this type of plasmas.

The voltage and electric field were distributed periodically according to the priority of the applied voltage.

All the diagnosed parameters (electrons density, mean electron energy, electrons current density, ions current density and total plasma current) depend on the type of the dielectric material.

The active regions of the DBD plasma placed near the boundary of dielectrics which cover the electrodes.

\section{References}

[1]. Kogelschatz U., Baldur E., and Walter E., "Dielectric Barrier Discharges. Principle and application", Journal de Physique, 07 (C4), C4-47-C4-66, 1997.

[2]. Mi Z., Yan L., and Yan-zhou S., "Study on the Characteristics of Dielectric Barrier Discharge and Dielectric Barrier Corona Discharge", Proceedings of the Third International Symposium on Computer Science and Computational Technology (ISCSCT '10), Jiaozuo, P. R. China,7(10), 492-494, August (2010).

[3] Dhali S.K. and Sardja I., "Dielectric-barrier discharge for the removal of SO2", IEEE International Conference on Plasma Science, 56(21), 166-255, 1989.

[4] Kogelschatz U., Baldur E., and Walter E., "From ozone generators to flat television screens: history and future potential of dielectric-barrier discharges", Pure Applied. Chemistry, 71(10), 1819-1828, 1999.

[5].Kogelshtz U., "Dielectric-barrier discharges their history discharge physics and industrial applications", Plasma chem. Plasma process, 33(1), 1-46, (2003).

[6] Mankour M., Belarbi A., Hartani K., "modeling of atmospheric glow discharge characteristic", Romanian Reports in Physics, 65(1), 230-245, 2013.

[7] Hagelaar G., and Pitchford L C., "Solving the boltzmann equation to obtain electron transport coecients and rate coecients for fluid models", Plasma Sources IOP Science Technology, 14(4), 722-733, 2005.
[8] Hagelaar G., "Modeling of Microdischarges for Display Technology", $\mathrm{PhD}$, Technische Universities Eindhoven, Eindhoven, p.10-11, 13-20, 2000.

[9] Farouk I., "Modeling and Simulations of DC and RF Atmospheric Pressure Nonthermal Micro Plasma Discharges: Analysis and Applications", PH.D, Drexel University, Philadelphia (UK), pp.39-41, 2009.

[10] Plasma Module Users Guide (C1998-2012 COMSOL, Protected by U.S. Patents http://www.comsol.com.19,518; 7,596,474; 7,623,991; and 8,219,373. Patents pending, Version COMSOL4.3a October 2012.

[11] Giovangigh V., "Mass Conservation and Singular Multicomponent Diffusion Algorithms" IMPACT of computing in Science and Engineering, 2(1), 73-97, 1990.

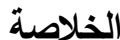

في هذا العمل نم دراسة التقريغ الكهربائي في فجوة بين لوحيين متوازيين يغطيهما عازل احد الالواح منصل بفولنية متتاوبة .VO فولت وبتردد .0 كيلو هيرتز والاخر موصول

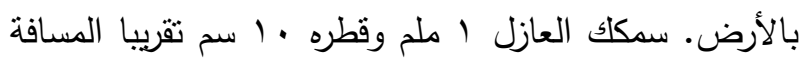
بين العازلين (الفجوة) r ملم مملوءة بغاز الاركون تم استخدام

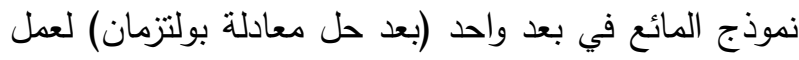
محاكاة حاسوبية لتشخيص خصائص البلازما التي ينتجها تفريغ حاجز العزل الكهربائي لا نواع مختلفة من المواد العازلة (التفلون, الزجاح, السيليكون).

ومن النتائج التي حصلنا عليها تم الحصول لعلى على تتخيص جيد من خلال دراسة خصائص انهيار الغاز التي تتمنل في حساب كل من الجهد والمجال الكهربائي, كثافة الالكترون, ومعدل طاقة الاكترون وكثافة تنار الايون

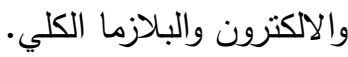

